\title{
Cenários reflexivos na prática de ensino da formação inicial de professores em Ciências Biológicas
}

\author{
Reflective scenarios in the teaching practice of pre-service biology \\ teachers
}

\author{
Rúbia Emmel ${ }^{1}$ \\ Maria Cristina Pansera-de-Araújo ${ }^{2}$
}

\section{Resumo}

A investigação-formação-ação é a proposta apresentada nesta pesquisa considerando suas contribuições no contexto da prática de ensino para a formação inicial de professores na licenciatura em Ciências Biológicas. A pesquisa teve como objetivo geral: conhecer o caráter constitutivo do currículo a partir da compreensão das relações entre as concepções de currículo e livro didático de licenciandos em Ciências Biológicas. Os movimentos formativos experienciados pelos sujeitos foram analisados nesta pesquisa, através das escritas narrativas em diários de bordo (participaram da pesquisa cinquenta e quatro licenciandos, o professor titular e a professora pesquisadora). As reflexões dos licenciandos desencadearam problemas formativos, apresentados nesta investigação em três cenários reflexivos: Cenário 1) Constatações das Relações entre Professores e Alunos; Cenário 2) As marcas e amarras das relações entre o/a Professor/a, o Livro Didático, o Currículo e a Licenciatura em Ciências Biológicas; Cenário 3) As transformações das concepções de currículo e livro didático no "ser professor". Portanto, o valor formativo das reflexões em histórias narradas, destacou a necessidade da formação inicial reservar um tempo maior aos estudos reflexivos das relações entre currículo e livro didático.

Palavras chave: prática de ensino; formação inicial; currículo; livro didático.

\section{Abstract}

Research-training-action is the proposal presented in this research considering their contributions in the context of teaching practice for pre-service biology teachers. The research had the general objective of knowing the constitutive character of the curriculum from the understanding of the relations between curriculum conceptions and didactic books of pre-service biology teachers. The formative movements experienced by the subjects were analyzed in this research, through the narrative writings in logbooks (fifty-four licensees participated, the titular professor and the researcher). The reflections of the pre-service teachers triggered formative problems, presented in this research in three reflective scenarios: Scenario 1) Findings of Relations between Teachers and Students; Scenario 2) The marks and ties of the relations between the Teacher, the Didactic Book, the Curriculum and the Degree in Biological Sciences; Scenario 3) The transformations of curriculum and textbook conceptions in "being a teacher". Therefore, the formative value of the reflections in narrated stories emphasized the need for initial training to allow more time for reflective studies of the relationship between curriculum and textbook.

Keywords: teaching practice; teacher pre-service; curriculum; textbook

\footnotetext{
${ }^{1}$ Instituto Federal Farroupilha | rubia.emmel@iffarroupilha.edu.br

${ }^{2}$ Universidade Regional do Noroeste do Estado do Rio Grande do Sul - UNIJUI | pansera@unijui.edu.br
} 


\section{Introdução}

Esta pesquisa teve como tema as contribuições da prática de ensino para a formação inicial de professores na licenciatura em Ciências Biológicas, nos estudos sobre a relação entre o currículo e o livro didático da educação básica. A pesquisa teve como objetivo geral: conhecer o caráter constitutivo do currículo a partir da compreensão das relações entre as concepções de currículo e livro didático de licenciandos em Ciências Biológicas.

Este tema foi proposto a partir: - do problema de pesquisa "Que indícios de constituição do conceito de currículo, pelos licenciandos em Ciências Biológicas, caracterizam o processo e identifica a associação ou não ao [uso do] livro didático como fonte organizadora deste currículo?"; e, - da definição da hipótese: os processos de formação inicial, mediados pela via da investigação-formação-ação, em contexto de um componente curricular de prática de ensino, permitem aos licenciandos diálogos críticos que (re)signifiquem o uso do livro didático e a complexa rede de relações entre professores em formação e o currículo em ação.

A investigação-formação-ação é a proposta que se apresenta para a formação inicial de professores, fundamentada em uma literatura que aponta a pesquisa como essencial, para a constituição do professor pesquisador. Os discursos de Elliott (1998) e Carr; Kemmis (1988) sobre investigação-ação, de Alarcão (2010) sobre "pesquisa-formação-ação" e de Güllich (2013) sobre investigação-formação-ação somam-se aos referenciais que sustentam o desenvolvimento da trajetória de estudos pedagógicos e didáticos do componente curricular "prática de ensino", para formação de um "professor reflexivo" (ALARCÃO, 2010).

As percepções sobre as relações de indissociabilidade entre a pesquisa-ação e o currículo sustentam a ideia de que investigação-formação-ação é uma proposta de inovação curricular. Assim como em McKernan (2009), a investigação proposta vai ao encontro da ideia de que o currículo pode ser entendido como um processo de pesquisaação e não como um produto resultante da elaboração de racionalistas técnicos.

\section{Percurso metodológico da pesquisa}

A pesquisa ocorreu em um município da Região Noroeste do Estado do Rio Grande do Sul (RS), em um Campus de uma Universidade, da Rede Pública Federal de Ensino, no Curso de Licenciatura em Ciências Biológicas, no componente curricular: "Prática de Ensino em Ciências/Biologia II: Currículo e Ensino de Ciências e Biologia".

Os preceitos éticos e de direito previstos na Resolução 466/2012 do Conselho Nacional de Saúde (12/12/2012), que regulamenta a pesquisa com seres humanos (BRASIL, 2012), foram respeitados, pois todos os participantes concordaram com o TCLE (Termo de Consentimento Livre e Esclarecido). Os participantes deste estudo foram orientados acerca dos objetivos e procedimentos da pesquisa expressos no TCLE, e tiveram seu direito de participar ou não da mesma preservado, bem como o sigilo e o anonimato. A fim de garantir a autoria e ao mesmo tempo o sigilo, os licenciandos foram nominados "L1 a L54". Suas falas e transcrições de escritas narrativas estão colocadas em destaque tipográfico itálico, entre aspas.

Os movimentos formativos experienciados pelos sujeitos foram analisados nesta pesquisa, através das escritas narrativas (CARNIATTO, 2002; CHAVES, 2000; REIS, 2004) em diários de bordo (participaram da pesquisa cinquenta e quatro licenciandos, o professor 
titular e a professora pesquisadora). Os diários de bordo são descritos na literatura internacional como um mecanismo que facilita o processo reflexivo (ALARCÃO, 2010; PORLÁN; MARTíN, 1997).

\section{Recolocando o livro didático no currículo e na formação da Licenciatura em Ciências Biológicas}

As análises estão organizadas para evidenciar como ocorre a relação entre o livro didático, os licenciandos, o professor titular, a professora pesquisadora e os professores de educação básica, no contexto da prática de ensino (na formação inicial) e como este processo influenciou a constituição dos conceitos de currículo pelos licenciandos ao visitar o lugar do currículo em ação. O que se pretende é recolocar a discussão e a problemática do livro didático, no contexto da formação de professores.

Esta investigação aproxima-se das ideias de Martins (2012), que considera o livro didático como representante de uma instância articuladora de diferentes vozes, horizontes sociais e conceituais, constituindo e materializando o discurso científico-escolar. Para a autora, o texto didático (expresso nos livros didáticos), materializa o discurso sobre Ciência na escola, considerando que este se "constitui em meio a tensões e negociações entre a natureza da Ciência de referência, os objetivos do ensino escolar e padrões de comunicação na sociedade" (MARTINS, 2012, p. 20). Uma análise destes discursos, expressos nas narrativas dos licenciandos, foi realizada a fim de reconhecer o lugar que o livro didático vem assumindo, no contexto da formação inicial dos professores de Ciências Biológicas.

Os licenciandos realizaram observações das aulas de Ciências Biológicas na educação básica, mais especificamente no Ensino Médio. A partir das observações e análises realizadas pelos licenciandos e registradas como narrativas nos diários de bordo, que tinham a pretensão de transformação, em movimento de investigação-ação crítica, buscouse as compreensões deles sobre o lugar do livro didático no contexto da educação básica, mais especificamente no currículo em ação.

Considerando que "o texto do livro didático de Ciências caracteriza elementos dos gêneros de discurso científico, didático e cotidiano" (BRAGA; MORTIMER, 2003, p. 59), cabe analisar o uso do livro didático pelos professores de Ciências Biológicas. Percebe-se que o livro didático é usado como fonte de pesquisa, de referência, de constituição curricular, de sugestão de atividades. Para tanto, é preciso ter cuidado, pois "os livros escolares exprimem a reelaboração dos conteúdos das diversas áreas de conhecimento a que se referem, mas o fazem de forma acentuadamente padronizada" (FRACALANZA, 2006, p. 178). Outra discussão que pode ser aventada por essa via está no conhecimento que o livro didático traz em seu enredo. Um conhecimento escolar e não científico como explicado por Lopes (2007; 2008), é insuficiente para formação do professor. Antes é um recurso para didatização das Ciências para o aluno.

Cabe recolocar a discussão de quanto o currículo é entendido como sinônimo de conteúdo. O currículo-conteúdo é, pois, uma simplificação das mais presentes no discurso de professores, como pode ser percebido nos conteúdos dos planos de ensino, por vezes, copiados dos próprios livros didáticos, ou quando precisam manifestar suas impressões sobre o que é currículo tendem a reduzi-lo a uma lista de conteúdos. Parece possível afirmar que o uso do livro tem impulsionado e reforçado essa concepção de currículo como conteúdo. 
Em relação aos aspectos limitantes das práticas de ensino, que decorrem do uso do livro didático, podemos considerá-lo como elemento vinculado aos processos de formação inicial e continuada, pois, um professor que não refletiu sobre este recurso didático, considerado por Lopes (2007) o currículo escrito, ao encontrá-lo nas escolas, corre o risco de ser adotado por ele, representado por esta "maquinaria didática" (GERALDI, 1994). Essa recepção passiva e tácita do professor em relação ao livro didático, seu uso como ferramenta de ensino, de planejamento e currículo-conteúdo; expressa-se no discurso educacional analisado e permite apostar numa formação de professores (inicial e continuada) que se intensifica na produção de sentidos e significados sobre este recurso em relação à prática docente.

\section{As reflexões desencadeadas pelos cenários das observações das aulas}

Nas observações das aulas realizadas pelos licenciandos e registradas nos diários de bordo, destaca-se a importância deste instrumento, no processo formativo, pela produção de análises e reflexões. Parafraseando Porlán e Martín (1997), é fundamental, neste tipo de atividade, observar atentamente e registrar no diário de bordo as condutas, comentários e perguntas, pois estas podem revelar os interesses, as curiosidades e novas expectativas.

Assim, Nóvoa (1995) aponta para a necessidade de articulação entre a formação e os projetos das escolas, que foram, neste caso, desencadeados, numa perspectiva críticoreflexiva de pensamento autônomo sobre as práticas, autoformação, desde a observação das aulas pelos licenciandos, investigadores-ativos, analisando-as e registrando suas reflexões.

Ao fazer uma análise das narrativas dos licenciandos sobre as observações das aulas, percebe-se no contexto que adentraram e narraram, o enredo de três cenários reflexivos que podem ser compreendidos a partir dos licenciandos como cenários constituidores do currículo em ação, indispensáveis a organização curricular da educação básica.

Ao assumir o papel de investigadores-ativos, mas também professores pesquisadores do componente curricular, foi possível fazer as reflexões, que desencadearam problemas formativos, apresentados nesta investigação em três cenários reflexivos: Cenário 1) Constatações das Relações entre Professores e Alunos; Cenário 2) As marcas e amarras das relações entre o/a Professor/a, o Livro Didático, o Currículo e a Licenciatura em Ciências Biológicas; Cenário 3) As transformações das concepções de currículo e livro didático no "ser professor". Estes cenários reflexivos permitiram situar os contextos em diferentes temas e situações de formação inicial de professores da Licenciatura em Ciências Biológicas.

\section{Cenário 1: Constatações das Relações entre Professores e Alunos}

Os registros dos licenciandos ( $\mathrm{L} 30$ e L32), no diário de bordo, sobre a primeira aula observada, descrevem que foi realizada no laboratório, onde:

[...] os alunos observaram uma experiência que a professora tirou de um livro didático e os alunos estavam todos curiosos e ansiosos, pois seria a primeira vez que teriam contato com o microscópio (Narrativa em diário de bordo (NDB), L30 e L32, 24 de julho de 2015).

Já a segunda aula observada por eles foi na sala de aula, com:

[...] os alunos todos agitados e querendo chamar a atenção por nossa presença (NDB, L30 e L32, 24 de julho de 2015). 
As narrativas descrevem diferenças de comportamento dos alunos, conforme o lugar em que a aula acontece. O laboratório é um ambiente diferente da sala de aula cotidiana, que pode ter deixado os alunos curiosos, observadores, apreensivos, mais atentos. As aulas de Ciências observadas por L30 e L32 ocorriam no turno da noite, o que provocou uma narrativa reflexiva sobre este contexto:

[...] a turma tinha alunos que trabalhavam de dia, mas alguns tinham grande interesse em buscar, perguntar e aprender, ainda havia uns que só conversavam não faziam nada querendo chamar atenção, pegamos alguns cadernos que estavam incompletos folhas em branco e também tinha cadernos organizados, questões respondidas (NDB, L30 e L32, 24 de julho de 2015).

Evidenciam-se as narrativas de $L 30$ e L32, com intuito de mostrar que estas problemáticas não ocorrem somente no ensino noturno, mas são evidentes e mais complexas no ensino diurno, como também pode ser percebido nas narrativas abaixo:

[...] os alunos não respeitavam a professora, levantavam a hora que queriam e era muita conversa, a professora não tem domínio na turma, os alunos agem como se ela não estivesse na aula (NDB, L53, 24 de julho de 2015).

[...] não havia muita participação dos alunos, eles estavam inquietos e o ambiente era "desorganizado", havia bastante lixo no chão e as mesas e cadeiras não estavam organizadas em fila (NDB, L21, 24 de julho de 2015).

[...] a turma era muito agitada, um dos alunos era o mais bagunceiro, fazia gracinhas durante a aula (NDB, L29, 24 de julho de 2015).

[...] a falta de interesse dos alunos na aula era muito grande, muita conversa, brincadeiras, se jogavam bolinhas de papel, alguns com fone de ouvido, outros mexendo no celular, a professora pedia a atenção deles, mas não adiantava (NDB, L10, 24 de julho de 2015).

[...] os alunos são barulhentos, muitas conversas paralelas, e o professor pedia silêncio e atenção dos alunos, mas eles não prestavam atenção [...] as explicações do professor foram muito breves [...] percebi uma falta de interesse dos alunos perante o professor e o conteúdo (NDB, L33, 24 de julho de 2015).

[...] os alunos não foram tão participativos na aula [...] os alunos mostravam-se bastante dispersos (NDB, L36, 24 de julho de 2015).

[...] os alunos tem um comportamento bastante infantil, jogando papéis pela sala. Os alunos também ficavam caminhando pela sala, para copiar as respostas um do outro, durante as atividades (NDB, L4, 24 de julho de 2015).

[...] a maioria dos alunos ficou o tempo todo da aula conversando e fazendo brincadeiras entre colegas (NDB, L47, 24 de julho de 2015).

[...] durante a aula, os alunos eram inquietos, e conversavam muito, sobre outros assuntos que não eram daquela aula (NDB, L48, 24 de julho de 2015). 
[...] os alunos estavam conversando e brincando o tempo todo [...] a professora não tinha um controle e atenção dos alunos, era uma bagunça total, muitas brincadeiras e risadas (NDB, L52, 24 de julho de 2015).

os alunos era muito conversadores, e inclusive durante as explicações da professora [...] alguns meninos estavam com sono e durante a explicação se deitavam sobre a classe (NDB, L15, 24 de julho de 2015).

[...] os alunos eram agitados, e professora demorou mais de quinze minutos para fazer todos entrarem na sala de aula, sentar, se acalmar e fazer silêncio, para que ela pudesse dar inicio as atividades da aula (NDB, L1, 24 de julho de 2015).

No contexto explicitado pelas narrativas dos licenciandos, percebe-se o quanto a "heterogeneidade de comportamentos" (MEIRIEU, 2005) abala a estrutura escolar e as salas de aula dos professores. Conforme o autor, a heterogeneidade existe, mas é contida pela "homogeneidade de comportamentos e pela unidade de adesão às normas escolares" ( $p$. 49).

As narrativas expressam que já na formação inicial de professores, há uma preocupação dos licenciandos com as condutas e comportamentos dos alunos, com as diferenças, o que elucida conforme Meirieu (2005) que para aprender bem, os alunos precisam ser parecidos ou ser até iguais.

Como estão as relações dos professores com os alunos?

[...] em conversa com a professora, a mesma relatou que no ano letivo anterior, metade da turma havia reprovado em Ciências, sendo que 9 alunos da turma que observei eram repetentes (NDB, L50, 24 de julho de 2015).

[...] na minha opinião, falta um pouco de domínio da professora com os alunos" [...] "acho que devia ter mais aulas práticas, para ter integração, não tenho como afirmar, quem sabe a professora se sentiu incomodada com a nossa presença [...] não posso julgar, pois no futuro, seremos nós (NDB, L8, 24 de julho de 2015).

Embora a falta de interesse dos alunos pelas aulas, tenha a ver com a postura e métodos de ensino utilizados pela professora, conforme L8, estes fatores não são determinantes, pois a partir da narrativa de L23, questiona-se: mesmo a professora sendo atenciosa e explicando há falta de interesse?

[...] a maioria dos alunos tinha dúvidas em relação às doenças estudadas, e professora explicava e dava exemplos, era muito atenciosa com os alunos [...] quando estavam fazendo as atividades, alguns estavam se jogando bolinha de papel, outros conversando sobre outros assuntos, e alguns alunos falavam que já estavam com fome, e queriam saber o que iria ter de merenda (NDB, L23, 24 de julho de 2015).

L23 demarca bem as diferenças presentes na sala de aula, que sempre existiram na escola, mas que como professores, ainda não se aprendeu a "gerir classes heterogêneas", pois é "mais prático e eficaz ter alunos do mesmo nível" (MEIRIEU, 2005, p. 48).

As observações registradas revelaram a insegurança em ser professor, como expressa L19: 
[...] é preciso ter muita coragem e não abandonar a vida de professor, então me vejo futuramente como professora, ali exercendo a responsabilidade de ser professor, será que darei conta do recado? [...] será que vou sobreviver às críticas? Como farei para enfrentar todos os problemas que irão surgir em sala de aula? Será que não vou desistir? (NDB, L19, 24 de julho de 2015).

Ao adentrar a sala de aula, como licenciandos e investigadores ativos, para observar as aulas, acredita-se que foram com olhos amadurecidos e críticos, na complexidade de um processo. Alguns licenciandos foram alunos daqueles mesmos professores, que estavam a observar e talvez naquela mesma sala de aula, e voltam agora para a educação básica, noutra condição assumida, na perspectiva de ser professor. Uma nova postura assumida, que gera receio e insegurança, mas constitutiva do ser professor.

As aulas apresentam um esquema e um ritual, como está expresso nos próximos cenários, e, neste sentido, são estabelecidas as relações entre os professores e os alunos:

[...] alguns alunos estavam fora da sala de aula, passeando pela escola, e a professora foi buscar eles (NDB, L11, 24 de julho de 2015).

[...] o professor entrou na aula sem dizer um oi ou um bom dia [...] durante a leitura a maioria dos alunos não estava prestando atenção, não estava lendo, a maioria dos alunos não realizaram o dever de casa (NDB, L40, 24 de julho de 2015).

Nestas relações, há por parte dos professores o reconhecimento de fatores externos, que interferem na aprendizagem dos alunos:

[...] conforme a professora os alunos faltam muito as aulas, não há interesse em estudar, não fazem as tarefas de casa, falta de apoio dos pais em acompanhar os filhos (NDB, L41, 24 de julho de 2015).

A partir das narrativas percebe-se que os licenciandos assumiram as mesmas expectativas dos professores que foram observados, como por exemplo: o não cumprimento do ritual das aulas, fugir dos limites de tempo estabelecido, falar e bagunçar durante as aulas, não fazer o tema de casa, não responder as atividades nas aulas. Os licenciandos se apropriaram dos discursos realizados pelos professores observados, sem realizarem suas próprias reflexões.

Outras narrativas trouxeram à tona o questionamento sobre as relações existentes entre a duração do período de aula e a possibilidade de aprendizagem:

[...] poucos alunos tinham interesse em aprender, alguns só queriam conversar e também chamar a atenção, alguns tinha o caderno em branco (NDB, L7, 24 de julho de 2015).

[...] percebi que aquela turma é muito desmotivada, poucos haviam feito a lição de casa, alguns nem se importam em abrir o caderno durante a aula (NDB, L49, 24 de julho de 2015).

Mas também havia turmas tranquilas, interessadas e participativas:

[...] a turma era tranqüila, sem muitas conversas paralelas, eles escutavam as apresentações, tanto é que participavam com perguntas e experiências pessoais (NDB, L42, 24 de julho de 2015).

[...] a professora explicava bastante os conteúdos e era atenciosa com todos os alunos [...] apenas um aluno não prestava muita atenção na aula, 
no geral todos interagiram bem e questionavam dúvidas com a professora (NDB, L35, 24 de julho de 2015).

[...] percebi que a professora é amiga da turma, possui respeito e consegue controlá-los (NDB, L29, 24 de julho de 2015).

[...] os alunos participavam das aulas com interesse, e realizavam as tarefas propostas pela professora, fazem perguntas, tem vontade de aprender (NDB, L43, 24 de julho de 2015).

[...] os alunos eram em geral bem participativos em aula, trabalhavam em cooperação, e indagavam muito a professora referente às dúvidas [...] a professora era muito atenciosa visitava os grupos de trabalho auxiliando os alunos e orientando eles em relação às atividades (NDB, L34, 24 de julho de 2015).

[...] enquanto os alunos respondiam a professora caminhava pela sala, perguntava se estavam conseguindo responder as perguntas, se tinham dúvidas e se precisavam de ajuda (NDB, L38, 24 de julho de 2015).

[...] os alunos eram bastante agitados, mas prestavam atenção na aula e fazem muitas perguntas (NDB, L24, 24 de julho de 2015).

[...] a professora passava entre as classes para auxiliar os alunos a procurar as respostas das questões (NDB, L28, 24 de julho de 2015).

[...] os alunos eram bem participativos e mudavam de assunto a todo momento, fazendo muitas perguntas diferentes ao professo [...] a sala de aula era bastante colorida, tinha bastante cartazes e trabalhos feitos pelos alunos" (NDB, L44, 24 de julho de 2015).

Acredita-se que, ao observarem as aulas, os licenciandos também revelaram um pouco das "culturas negadas e silenciadas no currículo" (SANTOMÉ, 2013). A seleção dos conteúdos culturais fica em mãos do livro didático, sendo o professor e o aluno, vozes ausentes no currículo escolar. Conforme Santomé (2013, p. 157) "criou-se uma tradição na qual os conteúdos apresentados pelos livros didáticos aparecem como os únicos possíveis, os únicos pensáveis".

Nas narrativas percebe-se que a homogeneidade e a padronização de comportamentos são características que foram salientadas pelos licenciandos. O padrão de tempo, as atividades, as formas de relações, as posturas e as condutas esperadas do aluno, as peculiaridades de cada aula, são descrições que demonstram o quanto há uma expectativa por um comportamento igual entre os alunos e um desrespeito pelas suas diferenças.

Cenário 2: As marcas e amarras das relações entre o/a Professor/a, o Livro Didático, o Currículo e a Licenciatura em Ciências Biológicas

Pelas narrativas dos licenciandos percebe-se o quanto o livro didático está presente na maioria dos momentos das aulas, como está em destaque tipográfico negrito, demarcando a narrativa de L29:

[...] a professora fez a correção do tema que se tratava de questões do próprio livro didático [...] nas respostas dos alunos, era fácil perceber que eram copiadas do livro didático, muitas vezes fazendo o uso de analogias 
indevidas como explicação [...] quando a professora fazia alguma questão para os alunos, estas eram iguais as do livro didático, mas com palavras diferentes [...] depois pediu que os alunos copiassem e respondessem mais questões do livro didático [...] marcou a data da avaliação, que será com consulta no livro didático [...] percebi que ao desenvolver a aula a professora não largou em nenhum momento o livro didático [...] ela me disse que não tinha plano de aula, então seguia a ordem do livro didático (NDB, L29, 24 de julho de 2015).

As analogias indevidas, referidas por L29, emergiram das categorias de análise dos livros didáticos, estudadas pelos licenciandos, que serviu de embasamento. Para L29 entender esta percepção, no contexto de observação da aula e trazer, em sua narrativa, necessitou dos conhecimentos relacionados aos conceitos, aprendidos sobre aquele conteúdo. Daí a importância, na formação inicial de professores de Ciências Biológicas, da prática de ensino, que pode ser um lugar de mediação entre os componentes curriculares da formação pedagógica e específica, em que os alunos possam perceber, que para ser professor carecem de ambos os conhecimentos. As escritas narrativas dos licenciandos denunciam um "aprisionamento" dos professores observados que permitiram que "o livro didático comandasse o processo pedagógico" (GERALDI, 1993, p. 279):

[...] acredito que as aulas que assisti foram pouco produtivas, pois a professora fez somente atividades do livro didático, e em todas as respostas ela se referia em suas explicações ao livro didático [...] a professora ficou o tempo todo com o livro didático na mão e quando os alunos respondiam alguma questão errada ela os fazia abrir o livro didático e mostrava aonde estava a resposta correta (NDB, L27, 24 de julho de 2015).

[...] observei que os alunos utilizavam como instrumento de pesquisa nas aulas os livros didáticos [...] ao observar o caderno de um aluno junto com - livro didático utilizado em aula, percebi que as atividades feitas no caderno pelo aluno eram as mesmas do livro, assim todos os conteúdos, eram uma seqüência do livro didático (NDB, L34, 24 de julho de 2015).

[...] a professora iniciou o conteúdo com a leitura de textos nos livros didáticos, e ia fazendo explicações aos alunos, conversando, perguntando e retomando as explicações sobre o conteúdo [...] os alunos fizeram exercícios dos livros didáticos e a professora corrigiu com eles no final da aula (NDB, L3, 24 de julho de 2015).

[...] observei que o texto utilizado para leitura, e todos os exercícios propostos eram do livro didático (NDB, L10, 24 de julho de 2015).

[...] iniciou a aula com a correção do tema de casa, que eram questões do livro didático [...] no segundo momento, fez a leitura de um capítulo do livro didático [...] ao final da leitura fez uma breve explicação do conteúdo, e pediu que os alunos entregassem ao final da aula 10 questões do livro didático (NDB, L40, 24 de julho de 2015).

[...] o professor iniciou a aula com a correção de atividades da aula passada [...]"realizou uma leitura de um capítulo do livro didático, durante a leitura o professor interrompia para fazer explicações [...] o professor pediu que os alunos fizessem 10 questões do livro didático [...] percebi 
que o material utilizado pelo professor na aula foi apenas o livro didático (NDB, L33, 24 de julho de 2015).

[...] a professora explicou o capítulo 9 do livro didático, através de alguns slides [...] depois os alunos fizeram questões do livro didático (NDB, L4, 24 de julho de 2015).

[...] houve a correção de atividades da aula passada, do livro didático [...] "a professora pediu que os alunos iniciassem as questões do livro didático sobre o assunto passado na aula" (NDB, L22, 24 de julho de 2015).

Estas análises das narrativas evidenciam é que eram aulas/livro didático (GERALDI, 1994), o que impõe a questão já apresentada por Geraldi (1994, p. 120) "qual é o lugar que o livro didático ocupa no currículo em ação?", e indo mais além, registra-se outra questão: "qual é o lugar que o professor ocupa no currículo em ação?" Este foi percebido pelos licenciandos, embora suas narrativas evidenciem o tempo todo o livro didático, não deixaram em momento algum de referir-se ao lugar do professor, sem dúvida o personagem central das observações feitas. Apesar da expectativa do foco ser observar as aulas, percebe-se que os licenciandos olharam muito mais para os professores, o que pode ser decorrência do lugar da formação inicial, em que iniciam a sua apresentação como futuros professores.

L9 identifica nas aulas observadas, que a professora procura outras formas, mas quem comanda o processo pedagógico (GERALDI, 1993, 1994) é o livro didático:

[...] a professora passou o conteúdo, usou um texto sobre fungos do livro didático e pediu que eles observassem as figuras do capítulo que falava dos fungos [...] a professora mostrou exemplos de fungos, pediu que os alunos observassem e para descrever a ela o que estavam observando [...] depois ela fez um experimento do livro didático com os alunos [...] também continuou suas explicações sobre o conteúdo, explicando características do Reino Fungi [...] na segunda aula a professora pediu que os alunos fizessem leituras sobre o conteúdo no livro didático, após fez perguntas oralmente para os alunos, que podiam procurar as respostas no livro didático (NDB, L9, 24 de julho de 2015).

Nas narrativas L49 e L47 conseguem fazer uma relação do padrão de tempo das aulas, da qualidade e do aproveitamento do tempo:

[...] durante as aulas a professora acaba fazendo apenas um repasse do conteúdo do livro didático a seus alunos, seria aquela aula que extrapola os limites de uma aula tradicional, sendo assim uma aula copiada, em que o livro é a principal ferramenta de ensino [...] em duas aulas a professora fez somente correção de exercícios do livro didático (NDB, L49, 24 de julho de 2015).

[...] os alunos utilizaram 2 períodos de aulas para resolver 3 questões do livro didático (NDB, L47, 24 de julho de 2015).

Questiona-se: como está o tempo do ensino em nossas escolas? Neste tempo de aulas decorrem de fato aprendizagens? De que tipo? Estas são consideradas pelo professor? Como o professor considera o tempo das aulas? Preocupações evidenciadas também na narrativa de L29: 
[...] como será o processo de ensino-aprendizagem dos alunos? [...] minha aprendizagem poderia ter sido mais significativa caso meus professores fossem adeptos de outros métodos, que não só usando o livro didático (NDB, L29, 24 de julho de 2015).

E em atenção especial as narrativas de L46, L48 e L17:

[...] a professora solicitou que os alunos copiassem do livro didático, o desenho do ciclo reprodutivo do Reino Plantae [...] a professora ditou algumas questões para serem pesquisadas as respostas nos livros didáticos [...] a professora foi muito tradicional e uso do livro didático esteve presente em muitos momentos (NDB, L46, 24 de julho de 2015).

[...] os alunos entregaram para a professora um desenho sobre o ciclo reprodutivo das plantas, que tinha no livro didático, então o desenho foi copiado do livro didático [...] a professora passou questões no quadro, e pediu que os alunos respondessem pesquisando no livro didático (NDB, L48, 24 de julho de 2015).

[...] a professora utilizava vários livros didáticos com os alunos [...] os alunos copiavam os textos dos livros didáticos no caderno, assim também perguntas e respostas do livro didático [...] a professora tem poucos recursos para ensinar então aproveita tudo o que tem (NDB, L17, 24 de julho de 2015).

Reafirma-se que para o ensino reflexivo, que deseja alunos reflexivos, o professor estimula-os pelas suas atitudes, que podem propiciar o exercício da imaginação e da criatividade. Neste contexto, a cópia de textos e de desenhos, pode se tornar atividade tácita, repetitiva e sem muito significado, o que não permite a formação de sujeitos reflexivos. Se os professores descreveram nas propostas dos Projetos Políticos Pedagógicos que suas escolas pretendem promovem uma educação reflexiva, eles devem organizar atividades, em suas aulas, que possibilitem avançar no conhecimento e nas interlocuções.

Destaca-se a escrita narrativa de L38, em que a professora trazia outros materiais além do livro didático, já que as temáticas em foco não constavam do mesmo. Porém, o ensino nas aulas observadas girava em torno do livro didático:

[...] as questões do tema eram do livro didático [...] a professora trouxe cópias de um texto para os alunos e disse que esse texto não havia no livro didático [...] trouxe uma tabela com a classificação dos platelmintos e também disse que essa tabela não havia no livro didático (NDB, L38, 24 de julho de 2015)

As narrativas dos licenciandos permitem identificar a complexidade do currículo em ação, nas suas observações constataram quanto o cotidiano escolar pode ser massacrante e tedioso (Geraldi, 1994):

[...] a professora iniciou a aula com a correção dos exercícios da aula anterior, que estavam no livro didático [...] a aula seguiu com encaminhamentos de exercícios do livro didático (NDB, L50, 24 de julho de 2015).

[...] para esta aula a professora utilizou o livro didático, usou para leitura dos capítulos que traziam os conteúdos que eram trabalhados, e explicava utilizando o livro didático [...] o que pudemos analisar foi que a professora 
era tradicional, pois se deteu somente com o livro didático, seguindo a experiência e os conteúdos tal qual o livro (Narrativa dos diários de bordo, L30 e L32, 24 de julho de 2015).

Eram aulas, em que o professor não desenvolvia propostas e adequações específicas para desenvolver cada um dos conteúdos. As narrativas demonstram que os professores "faziam tudo sempre igual", mas a cada aula o livro era a única referência usada, e direcionava a organização da aula:

[...] começou a aula corrigindo questões do livro didático que foram respondidas na última aula, depois de ter corrigido os alunos fizeram mais questões do livro didático [...] no outro dia foi tudo igual novamente correção e mais questões do livro didático [...] nas aulas que observei só teve livro didático e muitas questões para os alunos responder (NDB, L7, 24 de julho de 2015)

[...] a professora fazia uso do livro didático e da lousa [...] a maioria de suas atividades estavam relacionadas ao livro didático (textos e questões) [...] no decorrer da aula a professora passou questões do livro didático [...] novamente os alunos, após as correções das atividades da aula passada, ganharam mais questões do livro didático para responder (NDB, L35, 24 de julho de 2015).

[...] Na primeira aula observada a professora começou sua aula com a continuação do conteúdo que havia dado em outra aula umas atividades do livro didático [...]após as correções pediu que todos os alunos abrissem o livro e fizessem mais atividades do livro didático para começar na aula e terminar em casa [...]a segunda aula foi parecida com a aula passada, pois, teve correção das atividades com explicação em forma de esquemas feito no quadro e depois de corrigido e explicado pediu que seus alunos fizessem mais atividades do livro (NDB, L12, 24 de julho de 2015).

Observa-se nas narrativas acima, que os registros se repetem, demonstrando que as aulas de Ciências tornaram-se excessivamente livrescas e dependentes do livro didático (GÜLLICH, 2013), o que expropria o próprio trabalho docente. Muitas vezes o docente não percebe esta amarra (GERALDI, 1994), seja pelo grande número de turmas em que atua ou pela "maquinaria didática" que baliza sua ação:

[...] O livro didático foi utilizado como instrumento de pesquisa nas aulas observadas, era a única fonte de informação (NDB, L28, 24 de julho de 2015).

[...] os alunos fizeram exercícios do livro didático sobre o conteúdo, que foram corrigidos e após foram dados mais exercícios para os alunos pesquisarem as respostas nos livros didáticos (NDB, L52, 24 de julho de 2015).

[...] a professora baseava sua aula no uso de livro didático, leitura de textos e responder questões do livro [...] na primeira aula a professora aplicou uma avaliação sobre o conteúdo ensinado até o momento, e os alunos poderiam fazer com consulta no livro didático (NDB, L20, 24 de julho de 2015).

Estes excertos das escritas narrativas dos licenciandos evidenciam que o livro didático é o personagem central do currículo em ação. Este cenário expressa a relação perversa entre 
livro didático e professor, em que parafraseando Geraldi (1993), é possível perceber que muitas vezes, é o livro didático que adota o professor, e não o inverso.

Porém percebe-se, nas narrativas de L14 e L36, que alguns professores conseguem se desvincular do roteiro proposto pelo livro didático, sustentando-se em compreensões e elaborações em outras leituras:

[...] o professor corrigiu algumas questões do livro didático que os alunos fizeram de tema de casa [...] o professor abriu o livro didático no capítulo que falava sobre Fungos, Reino Fungi [...] fez explicações sobre o conteúdo, mas pouco foi usado o livro didático, pois o professor sabia o que falar, sabia tudo, estava na memória dele esta aula (NDB, L14, 24 de julho de 2015).

[...] os alunos detinham o livro didático em mãos, mas o professor não o manuseava e não parecia seguir o roteiro do conteúdo do livro (NDB, L36, 24 de julho de 2015).

Megid Neto; Fracalanza (2006) sugerem investimentos na ampla divulgação dos diversos estudos e pesquisas disponíveis, que contemplam a avaliação do livro didático e suas formas de utilização pelos professores e alunos. Ainda, os mesmos autores acreditam que através dos cursos de formação de professores seria possível aprofundar a discussão sobre as deficiências e os limites das coleções didáticas atuais, bem como estimular a produção coletiva. No caso desta pesquisa a formação inicial propiciou a análise do enredo e do conteúdo do livro didático, através da investigação de categorias a priori, o que fez L43 ao observar as aulas e ao escrever sua narrativa refletir sobre o livro didático utilizado nas aulas:

[...] no livro didático utilizado pela professora percebi a presença de algumas categorias, que estudamos e analisamos nas aulas da Prática de Ensino: linguagem infantilizada, excessividade de imagens, discriminação, excessividade de experimentos (NDB, L43, 24 de julho de 2015).

O uso do livro didático deveria ser um ponto de apoio da aula, mas não objetivo principal da aula, em que o professor pudesse, acrescentar outros textos e atividades. Como demonstram as narrativas de L18 e L41:

[...] a professora faz uso do livro didático, mas também deixa espaço para discussões do conteúdo, não trabalha apenas em sala de aula, vai a campo com os alunos e faz atividades no laboratório da escola (NDB, L18, 24 de julho de 2015).

[...] para responder as questões os alunos utilizavam o livro didático [...] o livro didático se faz presente, mas a professora também busca outros recursos para as aulas como internet e jornais (NDB, L41, 24 de julho de 2015).

Conforme expõe Bizzo (1998), o livro didático, embora se constitua em possível vilão no ensino, é um recurso amplamente distribuído em todo território nacional através do PNLD ${ }^{3}$. $\mathrm{O}$ autor relata que o material pode se caracterizar como facilitador do processo de ensino e

3

PNLD - Programa Nacional do Livro Didático 
contribuir na melhoria da prática docente. Porém, o professor não deve adotá-lo como sendo exclusivo, selecionando os tópicos apresentados, que estabeleçam interligações com sua realidade.

De modo geral, os licenciandos conseguiram detectar a transferência da condução do processo pedagógico, produzida pela presença e tipo de uso feito do livro didático nas aulas de Ciências, que observaram.

Cenário 3: As transformações das concepções de currículo e livro didático no "ser professor"

Embora o tempo de observação parecesse pouco ou curto, acredita-se que foi uma experiência marcante e única para os licenciandos, neste sentido, entre os cenários identificou-se este que trata das reflexões sobre a prática docente, que propiciaram as transformações das concepções e refletiram no "ser professor", realizadas pelos licenciandos em suas narrativas.

Em suas observações, L29 percebeu que o caderno era um instrumento de avaliação:

[...] a professora usa o caderno como instrumento de avaliação, talvez por isso os cadernos estejam bem organizados" (NDB, L29, 24 de julho de 2015).

Para além das reflexões de L29, salienta-se o fato de que na escola o que realmente importa não é o produto: exercícios, dossiês, exposições isso tudo não tem um interesse em si mesmo (MEIRIEU, 2005, p. 54). Um aluno não pode ser julgado por suas produções. Conforme o autor ninguém conserva por toda a vida seus cadernos escolares, "mas é de se esperar que todos conservem por toda a vida aquilo que puderam adquirir pelo trabalho de seus cadernos" (MEIRIEU, 2005, p. 54). Para Meirieu (2005), o que conta na escola não é a tarefa, mas o objetivo para a sua realização e o significado produzido pelos sujeitos que a executaram.

As reflexões realizadas pelos licenciandos permitiram ver-se como professores, observar as aulas como professores:

[...] como professor em formação, observar essa aula foi importante para que pudesse refletir sobre a ação docente [...] minha formação está permitindo perceber que Ciências da Natureza tem conteúdos que podem ser trabalhados em ambientes diferentes (laboratório, pátio da escola, trilhas ecológicas, entre outros) (NDB, L50, 24 de julho de 2015).

[...] me senti muito a vontade naquela turma e cheguei a imaginar eu no lugar da professora, imaginei como iria trabalhar com aquela turma e como tudo poderia ser diferente (NDB, L34, 24 de julho de 2015).

[...] se a professora usasse menos o livro didático e buscasse trabalhar outras atividades [...] observar as aulas foi muito proveitoso e significativo, uma marca positiva para o nosso fazer pedagógico, serve para o nosso crescimento enquanto alunas do Curso de Licenciatura em Ciências Biológicas e futuras professoras (NDB, L53, 24 de julho de 2015).

As narrativas revelaram a diversidade de contextos e formas de serem professores:

[...] a professora iniciou a aula com uma pergunta "qual diferença de platelmintos e nematelmintos?" [...] após as leituras e explicações com base no livro didático, a professora trouxe uma lombriga para que a 
turma pudesse observar e fazer perguntas [...] após a professora deu uma folha de exercícios [...] quando terminaram os exercícios a professora levou a turma para o laboratório de informática, para realizar jogos educativos sobre a temática verminose [...] percebi que a professora tenta utilizar todos os recursos que a escola oferece, usando de diferentes métodos de ensino (NDB, L43, 24 de julho de 2015).

[...] essa professora era muito acomodada, pois disse aos alunos que era impossível fazer aula prática sobre os protistas (NDB, L27, 24 de julho de 2015).

[...] a aula foi muito interessante, porque a professora não utilizou somente o livro didático, fez atividades práticas, conversou e explicou para os alunos (NDB, L9, 24 de julho de 2015).

[...] a professora poderia ter dado algumas atividades para os alunos fazer como tema de casa, pois os alunos levaram as duas aulas inteiras resolvendo as questões do livro didático (NDB, L13, 24 de julho de 2015).

[...] a professora faz uso de slides, traz eles ao assunto fazendo comparações com algo que eles conheçam, pois assim os alunos pareciam querer saber mais do assunto, o domínio da classe não é fácil, mas a professora gosta do que faz assim as atividades foram se tornando agradáveis e satisfatórias (NDB, L26 e L51, 24 de julho de 2015).

Em sua narrativa L21, conseguiu compreender aquela aula para além dos muros da sala de aula, que não é uma ilha, pois existem muitas formas de aprender:

"a professora esqueceu que os alunos têm formas diferentes de aprender, nem todos aprendem o conteúdo somente lendo textos e respondendo questões de livros didáticos" [...] "na escola há todo um espaço (que é do curso Técnico Agrícola) que a professora poderia utilizar para fazer observações, investigações e pesquisas com os alunos, sobre o conteúdo estudado" (NDB, L21, 24 de julho de 2015).

Nas narrativas abaixo está demarcado, que os licenciandos assumem, em seus escritos e reflexões, o lugar de professores:

[...] penso que nós professores devemos pensar mais em nossos alunos, não apenas em ter uma carga horária de 60 horas, e depois dizer que não sobra tempo para nada, foi uma escolha nossa essa profissão e podemos mudar essa realidade (NDB, L11, 24 de julho de 2015).

[...] fiquei decepcionada com aquela aula que observei [...] mas com tudo isso fica uma experiência para mim, que eu como futura professora, jamais vou fazer uma aula assim como presenciei, pois vou ser uma boa profissional e vou fazer com que meus alunos tenham gosto pelas minhas aulas (NDB, L10, 24 de julho de 2015).

[...] se eu fosse o professor teria explicado o conteúdo mais detalhadamente, faria exemplos no quadro, no dever de casa pediria para os alunos ler sua resposta, na explicação conteúdo poderia pedir que os alunos fizessem uma roda de leitura e explicaria o conteúdo de forma que os alunos interagissem na sala de aula. O professor precisa colocar o seu currículo em ação (NDB, L40, 24 de julho de 2015). 
[...] a aula observada me fez perceber que quando for professor, não seguirei o exemplo deste professor, elaborarei meus métodos de ensino, visando a participação do aluno juntos aos conteúdos (NDB, L33, 24 de julho de 2015).

[...] ao fazer observações pude me colocar um pouco no lugar de ser professor, percebi que não é nada fácil, tem que ter postura de professor [...] a professora parecia tradicional, mas não tenho certeza, pois não sei como ela é nos dias que não estive lá observando (NDB, L38, 24 de julho de 2015).

[...] para mim foi muito valida a observação, pois me coloquei na condição de ser professor, me fez refletir sobre suas ações, seu modo de ensinar, percebi o que funciona e o que na funciona na sala de aula (NDB, L37, 24 de julho de 2015).

L44 em sua narrativa evidencia o fato de que adentrou a escola para fazer a observação assumindo este lugar de licenciando que se constitui futuro professor:

[...] observar as aulas foi muito importante, para o meu crescimento e minha formação profissional, a observação das atitudes dos alunos e do professor diante das diversas situações ocorridas significou uma experiência positiva para meu aprendizado onde tive a noção de como será ser professor (NDB, L44, 24 de julho de 2015).

Uma vez que não se tratava da primeira entrada numa escola e numa sala de aula, mas sim da primeira vez que adentrava a escola, como docente em formação, procurando o lugar da docência, as observações realizadas e narradas marcaram os licenciandos:

[...] observei nas aulas, que ser docente não é uma tarefa simples, exige comprometimento com várias questões que se fazem presentes no dia a dia da sala de aula, ser docente não é só passar conteúdo, mas preocupar-se com o ensino e com a aprendizagem dos alunos também [...] conforme a professora falta tempo para o planejamento das aulas (NDB, L41, 24 de julho de 2015).

[...] observei que um período de tempo tão longo para responder somente 3 questões, não foi uma atividade muito satisfatória e também não despertou o interesse dos alunos e muito menos sua atenção [...] a professora poderia ter realizado atividades práticas, levado os alunos até o pátio da escola para observar o Reino Plantae [...] era preciso dedicação e empenho por parte da professora, que desafiasse os alunos e instigasse a buscar pela aprendizagem, poderia ter feito que os alunos participassem mais da aula [...]a realização da cópia de conceitos não é nem de longe o melhor método de ensino (NDB, L47, 24 de julho de 2015).

Nas narrativas dos licenciandos percebeu-se o quanto as relações entre o professor, o currículo e o livro didático foram demarcadas nos contextos das observações:

[...] a professora poderia ter ampliado o seu conceito de pesquisa, pois só no caderno e no livro didático ficou muito limitado (NDB, L48, 24 de julho de 2015).

"percebi que se os alunos não tivessem o livro didático, o acesso ao conhecimento não teria ocorrido, pois a escola não possui outro acervo 
de pesquisa, o entendimento do conteúdo seria mais vago ainda" (NDB, L28, 24 de julho de 2015).

"gostei de estar em uma sala de aula, mas acredito que a aula poderia ter sido diferente, não ter sido somente responder questões do livro didático" (NDB, L7, 24 de julho de 2015).

Neste sentido, as reflexões dos licenciandos contribuem para que, como futuros professores de Ciências, façam a crítica ao usar, e a crítica com o seu aluno, de modo que ressignifiquem os conceitos e as práticas, reelaborem, desconstruam a imagem e o significado do livro didático (GÜLLICH, 2013).

A falta de um roteiro de observação preestabelecido não impediu que os licenciandos ao chegarem nas escolas de educação básica, imbuídos de seu papel de investigadores ativos, reconhecessem e perseguissem as intencionalidades constituídas na interação com os colegas de universidade, revelando em suas escritas narrativas reflexões acerca do "ser professor":

[...] nas observações vi como realmente é ser professora, pois devemos estar dispostos e sempre atentos a responder as questões trazidas pelos alunos, buscar sempre a melhor forma para os alunos aprendam (NDB, L18, 24 de julho de 2015).

[...] me coloquei como professora e esse contato pra mim foi valioso, pois pude confirmar o gosto pela profissão de ensinar, foi uma experiência fantástica, poder observar uma aula, a professora e como ela deu a aula [...] é uma boa professora e que não mede esforços para explicar o conteúdo (NDB, L42, 24 de julho de 2015).

[...] gostei muito de observar as aulas, pois assim me coloquei no lugar de professor, e pude ver esta realidade de como ser e agir como professora, e fazer valer a pena cada minuto que estou nas aulas (NDB, L35, 24 de julho de 2015).

[...] enquanto professora, pretendo sempre refletir sobre a minha postura e atitudes em sala de aula, assumir o ensino e a pesquisa na sala de aula (NDB, L46, 24 de julho de 2015).

[...] a professora foi muito calma, conduziu as explicações sem levantar o tom de voz, utilizou de projeção de slides para explicar o conteúdo da aula, abria espaço para os alunos falar e questionar, passava exemplos no quadro (NDB, L1, 24 de julho de 2015).

[...] ao observar a aula senti vontade de ser professora, de ensinar, mesmo que esta escola não tinha muitos recursos, dá pra inventar aulas inovadoras em que os alunos gostem de aprender coisas novas e se dedicar aos estudos com força de vontade e não somente por obrigação (NDB, L17, 24 de julho de 2015).

[...] fiquei realizada com a observação que pude realizar, pois esta já era minha professora na educação básica, já conhecia a forma com que ela ensina, a professora sempre trazia experiências e atividades práticas, assim como nesta aula que observei, os alunos prestaram muita atenção na aula prática da professora (NDB, L24, 24 de julho de 2015).

[...] percebi que a professora não utiliza de nenhuma metodologia de ensino como a pesquisa, problematização e investigação, o que dificulta 
ainda mais o aprendizado dos seus alunos, pois se o professor não se utiliza de metodologias de ensino voltadas para a formação de sujeitos críticos, o aluno torna-se apenas um espectador da aula e receptor de conteúdo [...] é importante que o professor conheça a sua turma, o que está dificultando o aprendizado dos alunos [...] ser professor é ter compromisso com os alunos, perceber aspectos que dificultam seu aprendizado, conhecer a realidade dos mesmos, ter responsabilidade com a educação [...] ao observar a professora, percebi que ser docente não é um dom, mas sim uma construção continua de seu aprendizado [...] percebo que o professor deve inovar, a partir dos resultados rever sua prática, aperfeiçoá-la (NDB, L49, 24 de julho de 2015).

Acredita-se que foi muito importante para os licenciandos fazerem a observação das aulas, ainda que apenas descrevendo o que aconteceu nas mesmas, ao escreverem suas narrativas muitas reflexões foram desencadeadas, num exercício crítico, que transformou concepções, e permitiu os giros da espiral e dos cenários reflexivos, ou seja, o que influenciou e modificou concepções com relação ao livro didático e ao currículo.

Ao registrar as observações das aulas em narrativas, os licenciandos construíram suas representações da prática docente dos professores da educação básica, que por sua vez criou condições para uma reflexão sobre o currículo em ação, em aulas do componente curricular.

\section{Considerações Finais}

Acredita-se que os cenários reflexivos traduzem a espiral reflexiva desencadeada nos movimentos cíclicos da investigação-formação-ação, caracterizada pela amplitude de movimentos formativos do grupo de licenciandos, na investigação-ação crítica, propiciou a reflexão no contexto investigativo do componente curricular de prática de ensino. Os movimentos de estudos e pesquisas apontaram os contextos em diferentes temas e situações, na formação inicial de professores da Licenciatura em Ciências Biológicas, e fundamentaram os cenários reflexivos.

Portanto, o valor formativo das reflexões em histórias narradas, deixou transparecer e destacou a necessidade e a importância da formação inicial reservar um tempo maior à discussão acerca das relações entre currículo e livro didático, para que os futuros professores possam exercer a reflexão ao usar o livro didático e constituam-se autores do currículo.

Defende-se que a formação inicial use a investigação-ação, o diário de bordo e a escrita narrativa, para realizar um estudo que permita conectar teoria e prática, assumir a perspectiva de profissional reflexivo e tomar a investigação como uma dinâmica formativa para seu processo de formação e docência em Ciências Biológicas. 


\section{Referências}

ALARCÃO, I. Professores reflexivos em uma escola reflexiva. 7. ed. São Paulo: Cortez, 2010.

BIZZO, N. Ciências: fácil ou difícil? São Paulo: Ática, 1998.

BRAGA, S. A. de M.; MORTIMER, E. F. Os gêneros de discurso do texto de biologia dos livros didáticos de Ciências. Revista brasileira de Pesquisa em Educação em Ciências, v.3, n.3, set/dez. 2003.

BRASIL. Ministério da Saúde. Conselho Nacional de Saúde. Diretrizes e normas regulamentadoras da pesquisa envolvendo seres humanos: resolução 466/2012 Brasília (DF). 12p. Disponível em: <http://conselho.saude.gov.br/resolucoes/2012/ Reso466.pdf>. Acesso em: 23 nov. 2013.

CARNIATTO, I. A formação do sujeito professor: investigação narrativa em Ciências/Biologia. Cascavel: Edunioeste, 2002.

CARR, W.; KEMMIS, S. Teoria crítica de la enseñanza: investigación-acción en la formación del profesorado. Barcelona: Martinez Roca, 1988.

CHAVES, S. N. A construção coletiva de uma prática de formação de professores de Ciências: tensões entre o pensar e o agir. Tese de doutorado. Campinas: Universidade Estadual de Campinas, 2000.

ELLIOTT, J. Recolocando a pesquisa-ação em seu lugar original e próprio. In: GERALDI, C. M. G.; FIORENTINI, D.; PEREIRA, E. M. A. (orgs.). Cartografias do trabalho docente: professor(a) pesquisador(a). Campinas: Mercado das Letras, 1998.

FRACALANZA, H. O ensino de Ciências no Brasil. In: FRACALANZA, H.; MEGID NETO, J. (orgs.). O livro didático de Ciências no Brasil. Campinas: Komedi, 2006.

GERALDI, C. M. G. A produção do ensino e pesquisa na educação: estudo sobre o trabalho docente no curso de pedagogia. 1993. Tese (Doutorado em Educação), Faculdade de Educação da Universidade Estadual de Campinas, Campinas, 1993.

GERALDI, C. M. G. Currículo em ação: buscando a compreensão do cotidiano da escola básica. Pro-posições, v. 5, n. 3, p. 111-132, nov. 1994.

GÜLLICH, R. I. C. Investigação-formação-ação em ciências: um caminho para reconstruir a relação entre livro didático, o professor e o ensino. Curitiba: Prismas, 2013.

LOPES, A. C. Currículo e epistemologia. ljuí: Unijuí, 2007.

LOPES, A. C. Políticas de integração curricular. Rio de Janeiro: Uerj, 2008.

MARTINS, I. Analisando livros didáticos na perspectiva dos estudos do discurso: compartilhando reflexões e sugerindo uma agenda para a pesquisa. in: MARTINS, I. (coord.). O livro didático de Ciências: contextos de exigência, critérios de seleção, práticas de leitura e uso em sala de aula. Rio de Janeiro: [s.n.], 2012.

MCKERNAN, J. Currículo e imaginação: teoria do processo, pedagogia e pesquisa-ação. Porto Alegre: Artmed, 2009. 
MEGID NETO, J.; FRACALANZA, H. O livro didático de Ciências problemas e soluções. in: FRACALANZA, H.; MEGID NETO, J. (orgs.). O livro didático de ciências no Brasil. Campinas: Komedi, 2006.

MEIRIEU, P. O cotidiano da escola e da sala de aula: o fazer e o compreender. Porto Alegre: Artmed, 2005.

NÓVOA, A. Formação de professores e profissão docente. in: NÓVOA, A. (coord.). Os professores e a sua formação. Lisboa: Dom Quixote, 1995.

PORLÁN, R.; MARTíN, J. El diario del professor: um recurso para investigación em el aula. Diáda: Sevilla, 1997.

REIS, P. Controvérsias sócio-científicas: Discutir ou não discutir? Percursos de aprendizagem na disciplina de Ciências da Terra e da Vida. Tese de Doutoramento em Didáctica das Ciências, Universidade de Lisboa, Faculdade de Ciências, Departamento de Educação, 2004.

SANTOMÉ, J. T. As culturas negadas e silenciadas no currículo. in: SILVA, T. T. Alienígenas na sala de aula: uma introdução aos estudos culturais em educação. 11. ed. Petrópolis: Vozes, 2013. 